\title{
INTEGRATION OF FMECA AND STATISTICAL ANALYSIS FOR PREDICTIVE MAINTENANCE
}

\author{
Rabia Ghani ${ }^{\circ}$ \\ Department of Manufacturing Engineering \& Management, NUST PNEC, Karachi, Pakistan.
}

\begin{abstract}
:
The estimation of time-to-failure of machines is of utmost importance in the Manufacturing Industry. As the world is moving towards Industry 4.0, it is high time that we progress from the traditional methods, where we wait for a breakdown to occur, to the prognostics based methods. It is the need of the era to be aware of any incident before it occurs. This study provides application of Statistical-based Predictive maintenance. A BOPP Production line has been considered as a case study for this research. Since the inception of the line in 2013 , it is evident that $60 \%$ of breakdowns are due to lack of maintenance and timely replacement of bearings. Therefore, the research is based on the application of FMECA (Failure Modes, Effects and Criticality Analysis) to determine which bearing in the production line is most prone to failure and determination of which statistical model best fits the failure data of the most critical bearing. The result provides the best distribution fit for the failure data and the fit can be utilized for further study on RUL (Remaining Useful Life) of the bearing through Bayesian Inference.
\end{abstract}

Keywords: FMECA (Failure Modes, Effects and Criticality Analysis), Rayleigh Distribution, Predictive Maintenance, BOPP Production Line, Bearings, Time to Failure.

Cite as: Ghani, R. (2021). Integration of FMECA and Statistical Analysis for Predictive Maintenance. J App/ Res Eng Technol \& Engineering, 2(1), 33-37. https://doi.org/10.4995/jarte.2021.14737

\section{Introduction}

\subsection{Predictive Maintenance}

In the research conducted in the late 90's, Predictive maintenance was defined as the maintenance policy which is developed through the physical parameters of a machine which are continuously or alternatively sensored, measured and recorded to fulfill the requirement of supporting, assessing, validating information to help in making decisions in favor of the maintenance and operation of the machine. (Rao, 1996).

As a policy of maintenance, it is divided into two wide categories according to its application and user requirement:

Statistical-based Predictive Maintenance (SBM) is the first category of Predictive Maintenance.

The application of this maintenance policy is conducted through the data of breakdown and stoppages. Through this data, statistical model is developed to predict failure which in turn helps in creating a preventive maintenance policy. (Carnero, 2006).

Condition-based Predictive Maintenance (CBM) is the second category of Predictive Maintenance. In contrast to statistical based PM, this maintenance policy utilizes real-time data of the detoriation process of mechanical components to determine the overall health of the machine. (Carnero, 2006).
In this research paper, SBM is considered. The main reason behind this selection is that in the case of CBM, a maintenance action is taken only after the validation of one or more than one conditions depicting detoriation of the machine or process. This maintenance policy relies on continuous monitoring of the machine or the process. The maintenance activity cannot be planned beforehand. (Susto et al., 2012).

CBM requires tools such as vibration monitoring, thermography, tribology, process parameters, visual inspection, ultrasonic, and other non-destructive testing techniques, which are expensive. (Mobley, 2002)

In contrast to this, SBM does not require real time monitoring of the machine or process. It utilizes prior failure data to predict failure. This method also allows us to plan maintenance activity and inventory in advance.

Therefore, in this study statistical tools are used through recorded failure data. This methodology is economical and requires less tools as compared to Condition-based predictive maintenance.

The BOPP Production line which is considered as a Case Study for SBM, is part of a Production Plant consisting of 22 machines. Out of 22 , this production line had been considered due to its market share and profitability. The production line is divided into 5 sections where, Transverse Direction Orienter Section is with the most number of failures per annum. Through record keeping, it was confirmed that breakdown is due to the bearing 
failure within this section of the production line. There are 8 types of bearings installed in this section. Through this study, the most critical bearing was determined out of 8 bearings through FMECA and its failure data was fitted on a distribution model to determine the parameters. These parameters are the main source to predict time to failure of any future state.

\subsection{FMECA (Failure Modes, Effects and Criticality Analysis)}

FMECA is a simple tool to narrow down issues and formulate objectives to implement corrective actions to resolve them. This tool consist of three main steps, Identify, Prioritize and Formulate.

The three steps can be elaborated as follows (Carlson, 2014):

- Identify and fully understand potential failure modes and their causes, and the effects of failure on the system or end users, for a given product or process.

- Prioritize the issues for corrective actions after assessing the risk associated with the identified failure modes, effects and causes.

- Eliminate the issues by addressing the concerns having the highest priority by carrying out corrective actions.

Initially, FMEAs were used primarily as a safety analysis on the system hardware after the design was nearly complete. This application meant that any problems uncovered by the analysis were likely to be extremely expensive to fix. Recent refinements in the methodology have expanded the types of failures that can be analyzed to include functional failures in a functional representation of the system, failures of software components, and failures in the processes through which a product is built or maintained. (Becker \& Shipley, 2002)

The Transverse Direction Orienter (TDO) section had 8 types of bearings installed. To determine the most critical bearing FMECA was performed.

In this study, FMECA is used as a supporting tool along with statistical analysis to solve a problem. The goal of FMECA is to obtain failure conditions, determine the most critical conditions and eliminate them by providing compensating provisions. Failure Mode and Effects Analysis (FMEA) and the Criticality Analysis (CA) are two analysis which make up the FMECA. Firstly, various failure modes and their effects on the machine or process are assessed through FMEA. After which CA is conducted to prioritize the failures based on three factors that are severity of each effect of failure (S), likelihood of occurrence for each cause of failure (O) and likelihood of prior detection for the cause of failure (D). The process of prioritization is conducted by a subjective ranking procedure which provides us with a Risk Prioritization Number (RPN) where RPN $=\mathrm{S} \times \mathrm{D} \times \mathrm{O}$. (Sahoo et al., 2014).

\subsection{Statistical Model}

The bearing having the highest probability of failure that is highest RPN was expected to have a failure rate of increasing nature. And as the bearing detoriates with time, it becomes more susceptible to failure. The failure rate function would have a bath-tub shaped curve where there is a possibility of infant mortality. In the case of this data, the time during which the data is recorded is long after the infant mortality state. Therefore, the possibility of infant mortality can be disregarded. The primary concern was the distribution of life of the bearing during its early life. Due to this, the distributions which, during early life data, have strictly increasing failure rates were considered such as Weibull, Rayleigh and Exponential distributions. But this also included lognormal distribution as well which fails the increasing failure rate test to verify the case. Once a distribution fitted well on the failure data, then parameters were distribution through which probability plots could be generated and failure-time distribution functions. (Muller, 2003)

\subsubsection{Weibull Distribution and its relation to Rayleigh and Exponential Distribution}

The most commonly used distribution used in life data analysis is Weibull Distribution. As mentioned in 1.3, the failure rate does not have a possibility of infant mortality therefore a bath-tub shaped curve would not exist and Weibull distribution is not a good fit for data sets with bath tub shaped failure rates. (Merovci \& Elbatal, 2015).

It is a well-suited model for failure data of mechanical equipment. The different values of the two parameters, shape and scale, of this distribution showcase different behaviours. The shape of the PDF curve and failure rate is affected by the shape parameter, denoted by $\beta$. Following are the different behaviours observed at different values of $\beta$;

$0<\beta<1$, the failure rate is a monotonic, decreasing function.

$\beta=1$, the failure rate is constant for all values of $t$.

$\beta>1$, we can show that the failure rate is a monotonic, increasing function

In case of $\beta=1$, the Weibull distribution reduces to the memory-less distribution, the exponential distribution. Here is how exponential distribution is introduced. As it is mentioned, the failure rate is constant for all values of $t$ therefore this distribution is used to represent process or systems with an assumption of having constant failure rate. It is considered as a special case of Weibull distribution. The failure rate in this distribution is denoted as $\lambda$, which is a constant. Similarly, exponential distribution has two parameters, scale and location, denoted as $1 / \lambda$ and $y$ respectively. (Muller, 2003).

In case of $\beta>1$, the Weibull distribution creates a special case called as Rayleigh Distribution, where $\beta=2$. As it is mentioned, the failure rate is an increasing function. Rayleigh distribution has two parameters, scale and location, denoted as $\lambda$ and $\gamma$ respectively.

\subsubsection{Lognormal Distribution}

Usually lognormal distribution is used in case of design probability, material strengths, assessing fatigue. When 
the natural logarithms of time-to-failure data is normally distributed only then this distribution is used. This distribution has two parameters, $\mu$ which is the location parameter, and $\sigma$ which is the scale parameter. It is closer to normal distribution but it is essential to explore all possibilities and validate the usage through trial. (Muller, 2003).

\section{Methodology}

The research is based on a 5-step process. The author acquired the failure of data of 8 bearings from the BOPP production line from 2013 to 2016 from the Maintenance department. The data was then organized to be assessed and utilized for the study. Qualitative analysis was applied in 2-steps that are FMEA where failure effects, modes and the severity, detectability and occurrences of each failure were analysed. The step 2 of qualitative analysis was CA where a Risk Prioritization Number (RPN) was calculated through the analysis of FMEA.

Table 1: Severity, Detectability and Occurrence.

\begin{tabular}{|c|c|c|c|}
\hline Rank & Severity Criterion & Detectability Criterion & $\begin{array}{l}\text { Occurrence } \\
\text { Criterion }\end{array}$ \\
\hline 1 & $\begin{array}{l}\text { No effect on the } \\
\text { production }\end{array}$ & $\begin{array}{l}\text { Stethoscope, Alarm on } \\
\text { HMI or drive display, } \\
\text { Temperature Detection }\end{array}$ & $\begin{array}{c}\text { One } \\
\text { occurrence }\end{array}$ \\
\hline 2 & $\begin{array}{l}\text { Motor stops but } \\
\text { production continues }\end{array}$ & $\begin{array}{l}\text { Stethoscope, } \\
\text { Temperature Detection }\end{array}$ & $\begin{array}{c}\text { Two } \\
\text { occurrences }\end{array}$ \\
\hline 3 & $\begin{array}{c}\text { Section in which } \\
\text { motor is installed } \\
\text { stops but production } \\
\text { continues }\end{array}$ & Temperature Detection & $\begin{array}{c}\text { Three } \\
\text { occurrences }\end{array}$ \\
\hline 4 & $\begin{array}{c}\text { Complete Production } \\
\text { stoppage }\end{array}$ & No Detectability & $\begin{array}{c}\text { Four } \\
\text { occurrences }\end{array}$ \\
\hline
\end{tabular}

After the determination of the bearing with highest RPN, its time-to-failure data was assessed to obtain goodness of fit. As shown in Figure 3, 4 types of distribution models were applied on the data and their errors were calculated through RMSE. The distribution fit with least errors was considered as the best fit.

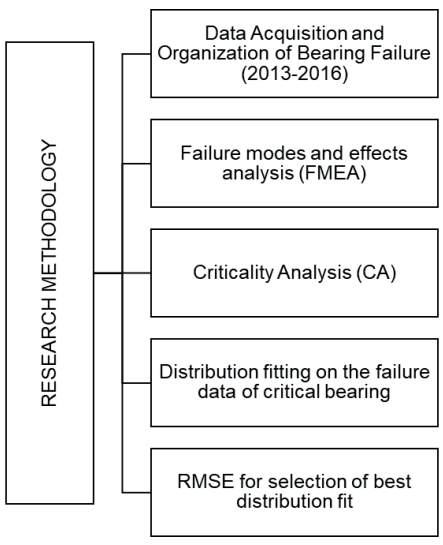

Figure 1: Flowchart to depict the Methodology.

\subsection{Data Acquisition and Organization}

The historical data was acquired from the Maintenance Department of Polymer manufacturing plant for the period 2013-2016. It consisted of type of bearing, installed location, failure effect, compensating provisions and the date of occurrence. Bearings were selected to conduct research as the failure occurrences at the BOPP Production line were majorly due to bearing failure.

\subsection{FMECA (Failure Modes, Effects and Criticality Analysis)}

FMECA is divided into two section that are FMEA (Failure Modes and Effects Analysis) and CA (Criticality Analysis). To select which type of bearing is the most critical for the Production line, the bearings were ranked based on severity, detection and occurrence as shown in Table 1 as part of the FMEA. The Risk Priority Number (RPN) for these bearings were determined as part of the CA. (Sahoo et al., 2014).

During assessing the failure modes, a fish bone diagram as shown in Figure 2, was also created for the assessment

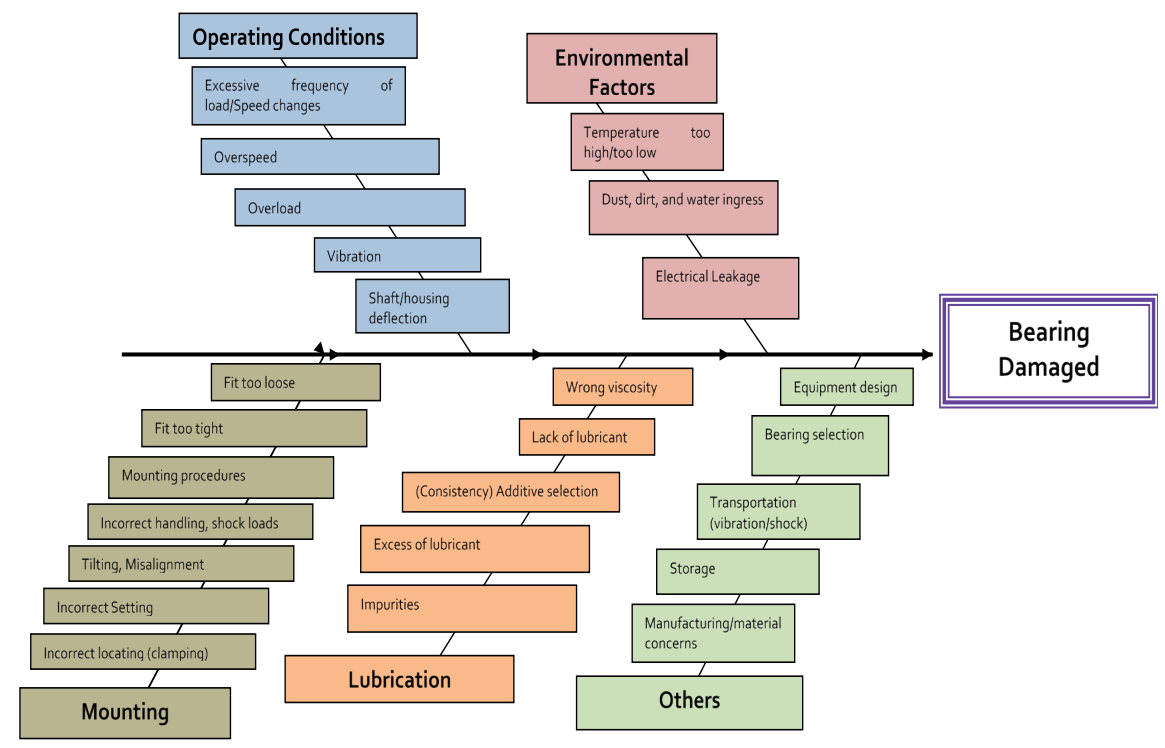

Figure 2: Fish Bone Diagram to assess Failure modes. 
to be more detailed for the major reasons of bearing failures at the BOPP Production line.

As shown in Table 2, $60042 \mathrm{Z} \mathrm{C3}$ has the highest RPN, 60 as compared to other 7 types of bearings.

Table 2: RPN (Risk Prioritization Number) Calculation.

\begin{tabular}{lcccc}
\hline $\begin{array}{l}\text { Identification } \\
\text { Number }\end{array}$ & $\begin{array}{c}\text { Severity } \\
(S)\end{array}$ & $\begin{array}{c}\text { Detectabili-ty } \\
(D)\end{array}$ & $\begin{array}{c}\text { Occurr- } \\
\text { ence }(O)\end{array}$ & $\begin{array}{c}\text { RPN } \\
(S \times D x O)\end{array}$ \\
\hline 6004 2Z C3 & 4 & 1 & 15 & 60 \\
\hline 62132 Z C3 & 2 & 3 & 4 & 24 \\
\hline 6212 2Z C3 & 2 & 3 & 4 & 24 \\
\hline 6308 2Z C3 & 4 & 2 & 2 & 16 \\
\hline 6209 2Z C3 & 4 & 1 & 4 & 16 \\
\hline 6306 2Z C3 & 2 & 2 & 3 & 12 \\
\hline 6205 2Z C3 & 4 & 1 & 1 & 4 \\
\hline 6002 2Z C3 & 4 & 1 & 1 & 4 \\
\hline
\end{tabular}

\subsection{Statistical Model}

The bearing, $60042 \mathrm{Z} \mathrm{C3}$, had the highest RPN and 25 data points were considered for statistical analysis.

\subsubsection{Distribution fitting on the failure data of critical bearing}

Time-to-Failure values of $60042 \mathrm{Z} \mathrm{C} 3$ were plotted against four types of distribution to determine goodness of fit namely, Weibull, Rayleigh, Lognormal and Exponential Distribution.

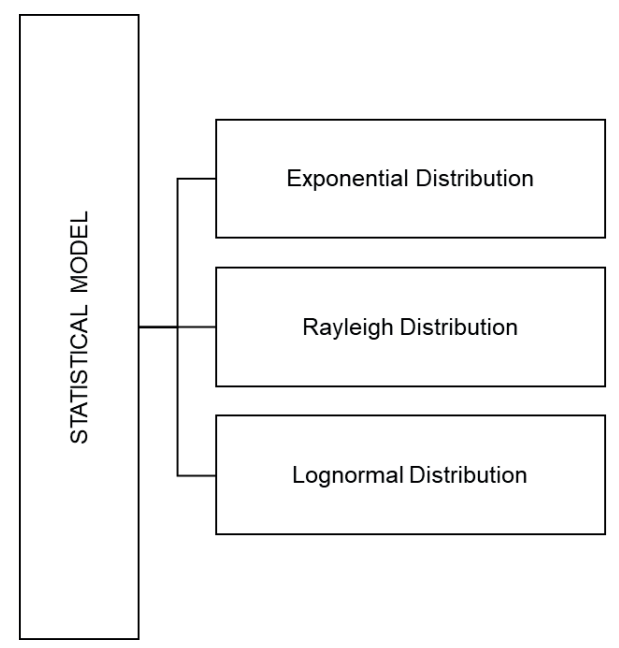

Figure 3: Distributions applied under Statistical Model.

\subsubsection{RMSE for selection of best distribution fit}

In order to determine the prediction efficacy of the distributions for the Time-to-Failure data of $60042 \mathrm{Z} \mathrm{C3}$, errors were computed.

As depicted in Table 3, the lowest value of RMSE determines the best distribution of the data. Therefore, Rayleigh distribution offers best approximation as compared to other distribution models considered.
Table 3: RMSE (Root Mean Square Error) to determine goodness of fit.

\begin{tabular}{lcccc}
\hline Distribution & RMSE & Mean & Variance & Parameters \\
\hline Rayleigh & 0.024215697 & 25.6697 & 180.047 & $\lambda=2$ \\
Lognormal & 0.025639813 & 27.3379 & 129.852 & $\mu=3.22817$ \\
\hline Weibull & 0.026463182 & 27.2918 & 96.9479 & $\beta=30.5514$ \\
\hline Exponential & 0.028024989 & 27.1667 & 738.028 & $\mu=27.1667$ \\
\hline
\end{tabular}

\section{Results \& Discussion}

A framework of qualitative and quantitative integration is developed in which FMECA is the qualitative analysis used to determine the bearing type with the highest probability of failure, then statistical modelling is applied where best distribution fit is determined through Root Mean Square Error (RMSE) to model the Time to Failure of the bearing with highest risk of failure.

First part of the result is depicted through the RPN calculation. It shows that $60042 \mathrm{Z} \mathrm{C} 3$ is the most critical bearing installed in the BOPP Production line. Second part of the result is the determination of distribution fit on the time-to-failure data of $60042 \mathrm{Z}$ C3. Rayleigh distribution had the least errors, when calculated through RMSE, as compared to errors of other distributions.

It is evident from the results that the BOPP Production line requires to maintain the conditions as well as the inventory of the 60042 Z C3 bearing and utilize Rayleigh distribution as the model to predict Time-to-failure of the bearing with highest risk of failure as compared to other distributions.

\section{Conclusion}

For improved reliability of any machine, a cost effective and less complex maintenance plan is required. By the utilization of FMECA and Statistical model, early detection of failure can reduce the chances of costly maintenance.

In future work the author plans to perform Bayesian Inference through the results of this research. The first step towards the start of the Bayesian inference is attaining a prior distribution of the data which is achieved through this conducted research.

The combination of FMECA and Bayesian Inference could be used for the prediction of Time to Failure of Roller Bearings of a BOPP production line.

\section{Acknowledgements}

The author would like to express great appreciation to Dr. Tariq Mairaj for his valuable suggestions. I would also like to extend my thanks to TriPack Films, QVISE Pvt. Ltd., NUST PNEC and PNEC NDT Lab for offering me the resources.

Finally, I wish to thank my parents, siblings, Engr. Iqra Johim and Dr. Hiba Rehman \& her family for their support and encouragement throughout the study. 


\section{References}

Becker, W.T., Shipley, R.J. (2002). Failure Analysis and Prevention. In W. T. Becker, \& R. J. https://doi.org/10.31399/asm. hb.v11.9781627081801

Carlson, C.S. (2014). Understanding and Applying the Fundamentals of FMEAs. 2014 Annual Reliability and Maintainability Symposium. Tucson: IEEE.

Carlson, C.S. (2016). Understanding and Applying the Fundamentals of FMEAs. Reliability and Maintainability Symposium.

Carnero, M. (2006). An evaluation system of the setting up of predictive maintenance programmes. Reliability Engineering and System Safety, 91, 945-963. https://doi.org/10.1016/j.ress.2005.09.003

Merovci, F., Elbatal, I. (2015). Weibull Rayleigh Distribution: Theory and Applications. Applied Mathematics \& Information Sciences, 9(5), 1-11.

Mobley, R.K. (2002). An Introduction to Predictive Maintenance. Woburn, Massachusetts, USA: Elsevier Science. https://doi.org/10.1016/B978-075067531-4/50006-3

Muller, C. (2003). Reliability Analysis of the 4.5 Roller Bearing. Monterey, California: Naval Postgraduate School.

Rao, B. (1996). Handbook of Condition Monitoring. Oxford: Elsevier Advanced Technology.

Sahoo, T., Sarkar, P.K., Sarkar, A.K. (2014). Maintenance optimization for critical equipments in process industries based on FMECA method. International Journal of Engineering and Innovative Technology, 3(10), 107-112.

Susto, G.A., Beghi, A., Luca, C.D. (2012). A Predictive Maintenance System for Epitaxy Processes Based on Filtering and Prediction Techniques. IEEE Transactions on Semiconductor Manufacturing, 25(4), 638-649. https://doi.org/10.1109/TSM.2012.2209131 